\title{
Ocorrência de Campylobater spp entre manipuladores de alimentos em cozinhas hospitalares de localidade urbana da região Sul do Brasil*
}

\author{
Occurrence of Campylobacter spp in food handlers of hospital kitchens \\ in urban area of Southern region Brazil
}

Iraci Tosin e Ruben Abreu Machado

\author{
Departamento de Ciência e Tecnologia de Alimentos da Universidade Federal de Santa Catarina.
} Florianopolis, SC - Brasit

\begin{abstract}
Pesquisa realizada em cozinhas hospitalares e institucionais do Município de Florianópolis, SC (Brasil) sobre a presença de Campylobacter em fezes de manipuladores de alimentos, demonstrou que a média de portadores foi de 6,2\%. De um total de 177 indivíduos pesquisados, os manipuladores assintomáticos, em cozinhas institucionais apresentaram indice de contaminaçăo superior àquele registrado em cozinhas hospitalares, ou seja, $10,5 e 2,2 \%$, respectivamente. Dentre os portadores, constatou-se uma estreita relação entre manipuladores do sexo masculino e faixa etária, que ficou entre 20 e 35 anos de idade. Observou-se forte indicativo, sugerindo maior prevaléncia de Campyiobacter spp em fezes de manipuladores do sexo masculino do que aquele do sexo feminino. Constatou-se, igualmente, uma certa tendéncia vinculando o grau de escolaridade do manipulador com seu estado de portador.
\end{abstract}

Campylobacter, isolamento \& purificação. Portador, epidemiologia. Manipulaçāo de alimentos.

\section{Introdução}

Vêm sendo amplamente estudadas nos últimos anos algumas espécies do goner Campylobacter, notadamente $C$. jejuni, $C$. coli e $C$. laridis, devido ao papel que desempenham no contexto das doenças humanas provocadas pelo consumo de alimentos contaminados ${ }^{32}$.

Nos países desenvolvidos, o Campylobacter jejuni não é normalmente encontrado como participante da flora. Ao contrário do que se observa em países em desenvolvimento, onde o saneamento básico é precário, e este microrganismo é isolado com frequiência bastante elevada de indivíduos assintomáticos s.7.16. $^{4}$.

No Brasil também tem sido observada a presença de $C$. jejuni e $C$. coli em indivíduos sem sintomatologia clínica, demonstrando a existência de portadores assintomáticos desses microrganismos ${ }^{13.19}$.

$\mathrm{O}$ aumento do número de doenças de origem alimentar deve-se, por um lado, à demanda elevada e constante de alimentos nos grandes centros urbanos e, por outro, à crescente necessidade de mão-de-obra, nāo raro, desqualificada. Soma-se a isso a introdução de novos tipos de produtos alimentícios e de embalagens, bem como a tendência atual de se consumir alimentos crus ou pouco cozidos visando à manutenção da qualidade nutricional e organoléptica dos mesmos.

Por tudo isso, os alimentos têm sido responsabilizados em muitos casos de toxinfecção, frequientemente ocorrendo em pequenos grupos de pessoas; porém essas eviđências são circunstanciais, uma vez que o cozimento é capaz de destruir a grande maioria de patógenos contaminantes de alimentos.

\footnotetext{
* Trabalho realizado com auxilio financeiro do Conselho Nacional de Desenvolvimento Científico e Tecnológico (CNPq) Processo. Parte de Dissertaçâo de Mestrado apresentada ao Departamento de Ciências e Tecnotogia de Alimentos da Universidade Federal de Santa Catarina, 1992.

Separatas/Reprints: Iraci Tosin - Departamento de Ciências e Tecnologia de Alimentos da Universidade Federal de Santa Catarina, Campus Universitário. Trindade - 88040-900-Florianopolis, SC - Brasil. Fax: (048) 231.9258

E.mail:ccblit@ccb.ufsc,br
}

Recebido em 6.7.1993. Reapresentado em 25.7.1995. Aprovado em 14.8.1995. 
$\mathrm{O}$ aparecimento de doenças de origem alimentar ocorre geralmente por contaminação cruzada, especialmente envolvendo saladas e outros alimentos crus provenientes de produtos avícolas ou de outras fontes ${ }^{3.25 .29}$.

Considerando-se que a maioria das pessoas envolvidas com a manipulação de alimentos, nas indústrias e nas cozinhas em geral, carecem de conhecimentos relativos aos cuidados higiênico-sanitários que devem ser seguidos durante e após a elaboração do produto, não se pode ignorar, desta forma, a possível presença de portadores assintomáticos de Campylobacter spp entre esses indivíduos. As práticas inadequadas de higiene e processamento por pessoas inabilitadas podem provocar a contaminação cruzada de alimentos, o que vem a se constituir em potencial de risco à saúde pública, especialmente nas cozinhas hospitalares.

$O$ presente trabalho teve como objetivo verificar a ocorrência de Campylobacter spp em portadores assintomáticos que manipulam alimentos em cozinhas hospitalares e institucionais.

\section{Material e Método}

Foram analisadas fezes de 177 indivíduos, manipuladores de alimentos em 4 cozinhas do tipo institucional e 4 do tipo hospitalar, que representaram cerca de $20 \%$ do número total de funcionários ligados diretamente a essa atividade. Esse número de indivíduos foi determinado em decorrência da receptiviđade e colaboração dos funcionários dos locais investigados.

Cada indivíduo pesquisado fomeceu material para a realização de uma única coprocultura e sub. meteu-se à aplicação de um questionário a respeito de seus dados pessoais. As amostras de fezes foram colhidas pelos próprios funcionários dentro de recipientes plásticos (Collectrs MR. Roche) contendo $15 \mathrm{ml}$ de solução glicerina cloreto de sódio tamponada, como meio de transporte e de preservação. ${ }^{3 !}$

Alíquotas de $1 \mathrm{ml}$ do inóculo, devidamente homogeinizado, foram transferidas para tubos contendo caldo de enriquecimento seletivo composto por: Caldo Brucella (DIFCO) suplementado com a, $15 \%$ de agar, $5,0 \%$ de sangue desfibrinado de cavalo, suplemento FBP $(0,025 \%$ de sulfato ferroso heptaidratado $+0,025 \%$ de metabissulfito de sódio $+0,025 \%$ de piruvato de sódio), acrescido ainda dos seguintes antibióticos (Suplemento seletivo para Campylobacter - MERK: vancomicina, $2,0 \mathrm{ml} / 1$; polimixina $\mathrm{B}, 50 \mathrm{ml} / \mathrm{l}$ e trimetoprim,
$10,0 \mathrm{mg} / \mathrm{l}$ ). As culturas em caldo foram incubadas em microaerofilia a $42^{\circ} \mathrm{C} / 48 \mathrm{~h}$, utilizando-se jarra anaeróbica (Permution do Brasil) e envelope gerador de gás (Anaerocult C MERK) ) $^{12.22 .28}$. Findo este período de incubação foram feitas estrias de isolamento dessas culturas em agar Brucella-FBP $+5,0 \%$ de sangue desfibrinado de cavalo + antibióticos (Suplemento seletivo para Campylobacter-MERK) $)^{10.15 .22 .23}$, seguido de nova incubaçāo a $42^{\circ} \mathrm{C} / 48 \mathrm{~h}$, em atmosfera modificada.

Foram selecionadas colônias típicas, desenvolvidas no meio seletivo, para exames em microscópio de contraste de fase. Após a caracterização, as colônias suspeitas foram inoculadas em caido Brucella-FBP e agar Brucella-FBP, respectivamente, sem sangue e sem antibióticos, seguido de incubação a $42^{\circ} \mathrm{C} / 48 \mathrm{~h}$, com o caldo sendo incubado em aerobiose e o agar em atmosfera microaerofila. Finalmente, as culturas presuntivas foram confirmadas pelos testes de produção de oxidase e catalase, produção de $\mathrm{H}_{2} \mathrm{~S}$, tolerância ao cloreto de trifenil tetrazólio, crescimento a $25^{\circ} \mathrm{C}$, $30^{\circ} \mathrm{C}$ e $42^{\circ} \mathrm{C}$, sensibilidade ao ácido nalidixico e resistência a cefalotina e hidrólise do hipurato ${ }^{22}$.

A identificação das espécies de Campylobacter spp foi feita de acordo com as características diferenciais descritas por Skirrow e col. ${ }^{28}$; Lovett e col. ${ }^{18}$; Park e col. ${ }^{22}$

\section{Resultados e Discussão}

Verificou-se que a oconência média de portadores assintomáticos de Campylobacter spp, entre os 177 manipuladores de alimentos em cozinhas hospitalares e institucionais pesquisados, foi de $6,2 \%$ (Tabela 1).

Verificou-se que entre os 91 manipuladores pesquisados nas cozinhas hospitalares, apenas 2 $(2,2 \%)$ eram portadores de Campylobacter spp, cuja espécie predominante foi a $C$. coli. (Tabela 1).

$O$ índice de portadores em cozinhas institucionais foi superior ao observado em cozinhas hospitalares. Dos 86 manipuladores estudados, 9 $(10,5 \%)$ eram portadores de espécies do gênero Campylobacter, sendo que $55,6 \%$ deles portavam C. jejuni e $44,4 \%$ C. coli (Tabela 1). Constatou-se, que o percentual de incidência de portadores de Campylobacter superior aos obtidos por outros pesquisadores, que ficou em tomo de 1,3 e $1,2 \%$, 35

Informaçỏes obtidas junto ao setor de nutrição dos locais pesquisados deram conta de que não há obrigatoriedade de realização rotineira de exames clínico-laboratoriais (atestado de saúde) para os 
Tabela 1 - Ocorrência e espécies de Campyiobacter em manipuladores de alimentos nas cozinhas pesquisadas.

\begin{tabular}{|c|c|c|c|c|c|c|c|c|c|c|}
\hline \multirow{3}{*}{$\begin{array}{l}\text { Tipos } \\
\text { de } \\
\text { cozinhas }\end{array}$} & \multicolumn{4}{|c|}{ Indivíduos } & \multicolumn{6}{|c|}{ Espécies isoladas } \\
\hline & \multicolumn{2}{|c|}{ Pesquisados } & \multicolumn{2}{|c|}{ Portadores } & \multicolumn{2}{|c|}{ c. jejuni } & \multicolumn{2}{|c|}{ C. coli } & \multicolumn{2}{|c|}{ C. laridis } \\
\hline & № & $\%$ & $N^{2}$ & $\%$ & $N^{2}$ & $\%$ & $\mathrm{~N}^{8}$ & $\%$ & $\mathrm{~N}^{2}$ & $\%$ \\
\hline $\begin{array}{l}\text { Hospitalar } \\
\text { Institucional }\end{array}$ & $\begin{array}{l}91 \\
86\end{array}$ & $\begin{array}{l}51,4 \\
48,6\end{array}$ & $\begin{array}{l}02 \\
09\end{array}$ & $\begin{array}{r}2,2 \\
10,5\end{array}$ & - & 55,6 & $\begin{array}{l}02 \\
04\end{array}$ & $\begin{array}{l}100 \\
44,4\end{array}$ & - & - \\
\hline Total & 177 & 100 & 11 & 6,2 & 05 & - & 06 & - & - & - \\
\hline
\end{tabular}

funcionários das cozinhas, sejam institucionais, sejam hospitalares. Por outro lado, não são freqüentes os cursos ou palestras oferecidos aos funcionários sobre noções básicas de higiene pessoal, bem como informaçōes adequadas sobre princípios técnicos e normas de segurança que devem ser observados durante e após a manipulação e processamento dos alimentos.

Os fatos acima mencionados podem, de alguma forma, justificar a presença de portadores assintomáticos nas cozinhas pesquisadas, porém não há como justificar maior ocorrência de Campylobacter em manipuladores de cozinhas institucionais.

Quanto à frequiência de isolamento de Campylobacter spp, não houve, em regra, um predomínio marcante de uma espécie sobre a outra (C. jejumi/C. coli), a partir das fezes dos 177 indivíduos pesquisados. As informações obtidas na literatura, quase sempre referem-se ao isolamento de C. jejuni como a espécie mais freqüentemente isolada em casos de surto epidemiológico, mas há poucas informações sobre o isolamento a partir de portadores assintomáticos ${ }^{11,14,20}$.

Constatou-se que, dos 33 indivíduos do sexo masculino pesquisados, $4(12,1 \%)$ apresentaramse como portadores de Campylobacter spp, enquanto que para 144 pessoas do sexo feminino, $7(4,8 \%)$ portavam espécies de Campylobacter. Dados semelhantes também foram observados por outros pesquisadores ${ }^{5.9 .27 .30}$ (Tabela 2).
Dos 15 indivíduos do sexo masculino pesquisados na faixa entre 20 a 35 anos (Tabela 2), 4 deles $26,7 \%$ ) eram portadores de Campylobacter spp, com um coeficiente de contigência $(\mathrm{O} \leq \mathrm{C} \leq 1)$ igual a 0,5329 o que reforça a hipotese de maior ocorrência dessas espécies de microrganismos nessa faixa etária ou próxima a ela. Resultados semelhantes foram observados por Blaser e col. ${ }^{6} \mathrm{e}$ Tauxe e col. ${ }^{31}$ Não foi encontrada qualquer relação entre faixa etária e maior ou menor prevalência de Campylobacter spp entre indivíduos do sexo feminino, conforme mostram os dados da Tabela 2.

Dentre os 177 indivíduos pesquisados, 156 $(88,1 \%)$ possuíam até o primeiro grau, dos quais $11(7,0 \%)$ apresentaram-se portadores de Campylobacter spp. Por outro lado, entre os 21 (11,9\%) possuíam até o segundo grau, nenhum deles apresentou o estado de portador, conforme Tabela 3.

Os dados apresentados na Tabela 4 mostram declínio acentuado no índice de portadores assintomáticos de Campylobacter spp, a medida em que os operários permanecem por mais tempo em suas atividades como manipuladores de alimentos.

Sabe-se que a grande maioria de matérias-primas utilizadas em cozinhas (frango, carne bovina e suîna dentre outras) estāo freqüentemente contaminadas por Campylobacter $\operatorname{spp}^{1,8,17,21,24,26}$ e que estas bactérias podem permanecer viáveis nas mãos dos operadores por um período de, pelo

Tabela 2 - Distribuição de portadores de Campylobacter spp, segundo grupo etário e sexo.

\begin{tabular}{|c|c|c|c|c|c|c|c|c|}
\hline \multirow{4}{*}{$\begin{array}{l}\text { Grupo etário } \\
\text { (Anos) }\end{array}$} & \multicolumn{8}{|c|}{ Sexo } \\
\hline & \multicolumn{4}{|c|}{ Masçulino } & \multicolumn{4}{|c|}{ Feminino } \\
\hline & \multicolumn{2}{|c|}{ Indivíduos pesquisados } & \multicolumn{2}{|c|}{ Portadores } & \multicolumn{2}{|c|}{ Individuos pesquisados } & \multicolumn{2}{|c|}{ Portadores } \\
\hline & $N^{p}$ & $\%$ & $\mathrm{~N}^{2}$ & $\%$ & $N^{2}$ & $\%$ & $\mathrm{~N}^{\mathrm{g}}$ & $\%$ \\
\hline $\begin{array}{l}20 \text { a } 35 \\
36 \text { a } 50 \\
\text { mais } 50\end{array}$ & $\begin{array}{l}15 \\
16 \\
02\end{array}$ & $\begin{array}{r}45,5 \\
48,5 \\
6,0\end{array}$ & $\begin{array}{r}04 \\
0 \\
0\end{array}$ & $\begin{array}{r}26,7 \\
0,0 \\
0,0\end{array}$ & $\begin{array}{l}50 \\
77 \\
17\end{array}$ & $\begin{array}{l}34,7 \\
53,5 \\
11,8\end{array}$ & $\begin{array}{r}03 \\
04 \\
0\end{array}$ & $\begin{array}{l}6,0 \\
5,2 \\
0,0\end{array}$ \\
\hline Total & 33 & 100 & 04 & 12,1 & 144 & 100 & 07 & 4,8 \\
\hline
\end{tabular}


Tabela 3 - Nivel de escolaridade dos manipuladores de alimentos das cozinhas pesquisadas.

\begin{tabular}{lccccc}
\hline & \multicolumn{4}{c}{ Indivíduos } \\
\cline { 2 - 3 } Escolaridade & \multicolumn{3}{c}{ Pesquisados } & & \multicolumn{2}{c}{ Portadores } \\
\cline { 2 - 3 } \cline { 6 - 7 } & No & $\%$ & & Ne & $\%$ \\
\hline Primelro grau & 156 & 88,1 & & 11 & 7,0 \\
Segundo grau & 21 & 11,9 & & 0 & 0,0 \\
\hline Total & 177 & 100 & & 11 & - \\
\hline
\end{tabular}

Tabela 4 - Distrlbuiçăo de portadores de Campylobacter $\operatorname{spp} V$ s tempo de serviço como manipulador de alimentos nas cozinhas pesquisadas.

\begin{tabular}{lccccc}
\hline & \multicolumn{4}{c}{ Individuos } \\
\cline { 2 - 3 } $\begin{array}{l}\text { Tempo serviço } \\
\text { Anos) }\end{array}$ & \multicolumn{2}{c}{ Pesquisados } & & \multicolumn{2}{c}{ Portadores } \\
\cline { 2 - 3 } \cline { 5 - 7 } & Ne & $\%$ & & Ne & $\%$ \\
\hline $0<5$ & 55 & 31,1 & & 07 & 12,7 \\
5 a 10 & 57 & 32,2 & & 03 & 5,3 \\
$>10$ & 65 & 36,7 & & 01 & 1,5 \\
\hline Total & 177 & 100 & & 11 & + \\
\hline
\end{tabular}

menos, 3 min após o contato com alimentos contaminados ${ }^{8}$. Dessa forma e considerando a carência de informações e treinamento adequados quanto a cuidados operacionais e pessoais a serem observados durante e após a manipulação de alimentos, é de se supor que tais indivíduos possam estar com certa freqüência expostos à presença de patógenos originários de alimentos, dentre eles a Campylobacter spp, inclusive por ser esta bactéria de natureza ubiquitária.

É provável, desse modo, que o contato, prolongado com tais microrganismos, tenha permitido o desenvolvimento de anticorpos correspondentes, conforme admitem alguns autores ${ }^{6.34}$.

Na literatura consultada nāo foi encontrada qualquer citação quanto à frequiência ou periodicidade de eliminação de Campylobacter spp,

\section{Referênclas Blbliográficas}

1. ALMEIDA, P.F \& SERRANO, M.A. Ocorrência de Campylobacter fetus subsp. jejunt em carcaças de frango e suínos. Rev. Microbiol., 18:279-83, 1987.

2. ARCHER, D.L. \& YOUNG, F.E. Contemporary issues: Diseases with a food vector. Clin. Microbiol. Rev., 1:377-98, 1988.

3. BEAN, N.H. \& GRAFFIN, P.M. Foodborne disease outbreak in the Lnited States. 1973- existindo, assim, a possibilidade de que o percentual de portadores encontrados tenha sido subestimado pelo fato de ter tido realizada apenas uma coprocultura de cada indivíduo examinado.

Alguns autores acreditam que o estado de portador, apresentando ou nāo sintomatologia de Campylobacter spp, não justifica o afastamento do funcionário do local de trabalho e que alguns cuidados higiênicos sanitários observados pelo manipulador, especialmente quanto à higienizaçåo das mãos, pode reduzir ou eliminar a possibilidade de riscos. Todavia, advertem que a situação deve ser diferente para as pessoas infectadas que apresentam quadro diarréico. Neste caso específico, o funcionário deve ser afastado do serviço até que o episódio tenha revertido ${ }^{5.6}$.

De qualquer forma, não deve ser descartada a possibilidade de um manipulador de alimentos, mesmo em caso assintomático, vir a constituir-se em fator de risco em uma cozinha, conforme também defende Archer e Young ${ }^{2}$.

Pelo levantamento realizado durante o desenvolvimento do presente trabalho constatou-se, contudo, que pelo menos $50 \%$ dos locais pesquisados nāo afastam seus funcionários de suas atividades, mesmo apresentando quadro clínico de diarréia. Esses fatos deixam patente que ainda é grande a falta de conscientização das pessoas encarregadas de cuidarem do bem estar coletivo, especialmente se considerarmos que os alimentos podem ser vetores de doenças quando contaminados por pessoas com pouca ou nenhuma habilidade em práticas higiênicas na manipulação desses alimentos.

Tendo em vista tratar-se de um grupo emergente ainda nāo completamente conhecido quanto ao seu poder de ação, devem ser tomados cuidados preventivos e de controle sistemático de portadores de Campylobacter spp, quando na função de manipuladores de alimentos, especialmente em cozinhas hospitalares.

1987: pathogens, vehycles and trends. $J$. Food Prot., 53:804-17, 1990.

4. BLASER, M.J.; BERCOWTZ, I.D.; LA FORCE, F.M.; CRAVENS, J.; RELLER, L.B.; WANG, W.L.L. Campylobacter enteritis: clinical an epidemiologic features. Ann. Interm. Med., 91:179-85, 1979.

5. BLASER, M.J. \& RELLER, L.B. Campylobacter enteritis. $N$. Engl.J. Med., 305:1444-52, 1981.

6. BLASER, M.J.; TAYLOR, N.D.; FELDEMAN, R.A. Epidemiology of Campylobacter jejuni infections. Epidemiol. Rev., 5:157-76, 1983. 
7. BLTZLER, J.P.; DEKEYSER, P.; DETRAIN, M.; DEHAEN, F. Related vibrio in stools. $J$. Pediatr., 82:493-5, 1973.

8. De BOER, E. \& HAHNÉ, M. Cross-contamination with Campylobacter jejuni and Salmonella spp from raw chicken products during food preparation. J. Food Prot, 53:1067-8, 1990.

9. DEMING, P.; GOUSSLIN-DETRAIN, $\mathbf{M}_{\text {; }}$ BUTZLER, J.P.i STERNON, J. Acute enteritis due to related vibrio: first positive stool cultures. J. Infect. Dis., 125:390-2, 1972

10. EHLERS, J.G.; CHAPPARO-SERRANO, M.; RICHTER, R.L.; VANDERZANT, C. Survival of Campylobacter fetus subsp. jejuni in cheddar and cottage cheese. J. Food Prot., 45:1018-20, 1982.

11. FIGUEROA, $G_{i}$ GALENO, $H_{\text {.; }}$ TRONCOSO, $M_{\text {i }}$ TOLEDO, S.; SOTO, V. Prospective study of Campylobacter jejuni infection in chilean infants evaluated by culture and serology. $J$. Clin. Microbiol, 27:1040-4, 1989.

12. GEORGE, H.A; HOFFAMAN, P.S.; SMIBERT, R.M.; KRIEG, N.R. Improveed media for growth and aerotolerance of Campylobacter fetus. J. Clin. Microbiol., 8:36-41, 1978.

13. JARAMILLO, H.F. Espécies termofilicas de Campylobacter aspectos bacteriológicos, epidemiológicos e patogênicos. Sào Paulo, 1983. [Tese de doutorado - Escola Paulista de Medicina].

14. JIMENEZ, V.P.; JONES, S.B.; ARCE, M.T.S; LEIVA, E.M.; MARTINEZ, L.R. Escherichia coli enteroxigena y Campylobacter jejuni en el sindrome diarreico agudo en lactentes chilenos. Bol. Oficina Sanit. Panam., 104:5162, 1988.

15. KAPLAN', R.L. Campylobacter. In: Lennette, E.; Balows, A.; Hausler, W.J.Jr.; Truant, J.P.; ed. Manual of clinical microbiology. $3 \mathrm{~d}$ ed. Washington, D.C.: American Society for Microbiology, 1980. p.235-41

16. LASTOVICA, A.J. \& PENNER, J.L. Serotypes of Campylobacter jejuni and Campylobacter coli in bacteremi hospitalized children. J. Infect. Dis., 147:592, 1983.

17. LEITÃO, M.F.F.; TANIWAKI, M.H; UBOLDIEIROA, M.N. Campylobacter jejuni e C. coli no trato intestinal e superficie de carcaças de frango recém-abatidos. Colet. ITAL, Campinas, 16:37-47, 1986.

18. LOVETT, J.; HUNT: J.M.; FRANCIS, D.W. e HZISICK, J. Isolation of Campylobacter species. In: Ls Food and Drug Administration (FDA). Bacteriological analytical manual. 6 th ed. Arlington, 1984. p. 1-9.

19. MENDES, E.N.; QUEIROZ, D.M.M.; CISALPINO, E.O.; PERES, J.N.; PENNA, F.J.; FIGUEIREDO FILHO, P.P. Ocorrência de Campylobacter jejuni em crianças com e sem diarréia em Belo Horizonte. Rev. Microbiol, 18:25-30, 1987.

20. MIKHAIL, I.A.; FOX, E ; HABERBERGER, R.L.Jr.; AHMED, M.H.; ABBATTE, E.A. Epidemiology of bacterial pathogens associated with infectious diarrhea in Djibouti. J. Clin. Microbiol, 28:956-61, 1990.
21. ODEKEYE, J.O.; ABDL, P.A.; BAWA. E.K Campylobacter ferus subsp. jejuni in poultry reared under different management systems in Nigeria. Avian Dis., 33:801-3, 1989.

22. PARK, C.E., SMIBERT, R.M.; BLASER, M.J.; VANDERZANT, C.; STERN, N.J. Campylobacter In: Speck, M.L. Compendium of methods for the microbiological examination of foods. 2 nd ed. Washington, APHA, 1984. p.386-404.

23. ROGOL, M.; SECHTER, I.; GREENBERG, Z.: MIZRACHI, R.; SHTARK, Y.: ALFI, S. Contamination of chiken meat and environment with various serogroups of Campylobacter jejuni/coli. J. Food Microbiol, 1: 271-6, 1985.

24. ROSEF, O.; GONDROSEN, B.; KAPPERLD, G Campylobacter jejuni and Campylobacter coli as surface contaminants of fresh and frozen poultry carcasses. Int. J. Food Microbiol., 1:205-15, 1984

25. SABRA, A. Diarréia aguda por Campylobacter jejuni. In: Diarréia na infância. Rio de Janeiro. Cultura médica Ltda, 1982. p. 115-27.

26. SAKLMA, H. Ocorrência de Campylobacter jejuni e Campylobacter coli em carnes e miúdos de frango crus comercializados na cidade de Sào Paulo. Sào Paulo, 1991. [Dissertaçào de Mestrado, Faculdade de Ciências Farmacêuticas, LSP].

27. SCHIMID, G.P.; SCHAEFER, R.E.; PLIKATIS, B.D.; SCHAEFER, J.R.; BRYNER, J.H.; WINTERMEYER, L.A.; KALFMANV, A.F. A one-ear study of endemic Campylobacteriosis in a Midwestern City: association with consumption of raw milk. J. Infect. Dis., 156:218-22, 1987.

28. SKIRROW, M.B. Campylobacter enteritts: the first five years. J. Hyg., 89:175-84, 1982.

29. SKIRROW, M.P. Epidemiology of Campylobacter enteritis. Int.J. Food Microbiol., 12:9-16, 1991.

30. SMITH, G.S. \& BLASER, M.J. Fatalities associated with Campylobacter jejuni infections. $J A M A$, 253:2873-5, 1985 .

31. TAUXE, R.V.; PEGLES, D.A.; HARGRETT-BEAN, N. Campylobacter infections. The emerging national pattern. $A m . \quad$. Publ. Healtb. 77:1219-21, 1987

32. TEE, W.; ANDERSON, B.N.; ROSS, B.C.; DWYER, B. Atypical Campylobacters associated with gastroenteritis, J. Clin. Microbiol, 25:1248-52, 1987

33. VALLADA, E.D. Manual de coprocultura de fezes. Sào Paulo. Livraria Atheneu, p.166, 1978.

34. WORLD HEALTH ORGANIZATION. Report of the WHO consultation on veterinary public health aspects of prevention and control of Campylobacter infection. Moscow, 1984 (UPV/CDC/FOS/84.1).

35. YOUNG, J.R.; CALLAHAN, P.; DREW, W.L. DADLEY, W.K. Diarrheal disease associated with isolation of Campylobacter fetus subsp. jejuni in adults. In: Current chemotherapy and infections disease: Proccedings of the 19 th. Interscience Conference on Antimicrobial Agents and Chemotherapy. Washington, D.C.: Americam Society for Microbiology. 1980. p. 939-40. 


\section{Abstract}

The lack of information regarding the occurrence of Campylobacter spp in food handlers and the potential public health risk involved, led to the undertaking of this work. The main purpose was to verity the presence of asymptomatic Campylobacter spp carries in food handiers of hospital and commercial foodservice kitchens. The average prevalence of carriers in kitchens was of $6.2 \%$; that in commercial foodservice kitchens (10.5\%) being higier than that found in hospital kitchens $(2.2 \%)$ in a universe of 177 individuals studied. A close relationship was found between Campylobacter spp, carriers of masculine sex and age group, wich was of about 20 to 35 years of age. There was also strong evidence suggesting a higler prevalence of Campylobacter spp among handiers of masculine sex than among those of feminine sex.

Campylobacter, isolation. Carrier state, epidemiology: Food handling. 